\title{
Dermatite atópica canina
}

\section{Canine atopic dermatitis}

\author{
Jakeline Paola Zanon'; Lucas Alécio Gomes²*; Gabrielle M. Marques Cury3; \\ Thalita da Costa Teles ${ }^{4}$; Adriane Pimenta da Costa Val Bicalho ${ }^{5}$
}

\section{Resumo}

A Dermatite Atópica Canina é uma dermatopatia de origem genética. Os cães acometidos tornam-se sensíveis aos antígenos presentes no meio ambiente, desenvolvendo grave reação alérgica, pruriginosa, que interferem na qualidade de vida do paciente. Devido ao seu caráter genético, esta é uma doença que na maioria das vezes não tem cura, apenas controle. O tratamento em geral é vitalício. Assim sendo, algumas drogas utilizadas, a exemplo dos corticosteróides, podem causar efeitos colaterais que em longo prazo, são capazes de diminuir o período de vida do animal. Desta maneira, o proprietário do cão portador de atopia, precisa ser esclarecido em relação às complicações e provável recidiva dos sinais clínicos, durante o período de tratamento. Portanto, presente artigo tem como objetivo uma revisão sobre Dermatite Atópica Canina, que está se tornando um problema crescente na clínica de pequenos animais.

Palavras-chave: Atopia, prurido, cão

\begin{abstract}
Canine Atopic Dermatitis is a skin disease of genetic origin. The affected dog becomes sensible to antigens presents in the environment, developing a severe alergic, pruriginous reaction, which intervenes in the quality of life of the patient. Because of the genetic character, that is an illness that in most of the times has no cure, just control. The treatment in general is lifetime. Thus, some used drugs, for example the corticosteroides, might cause collateral effects when used for a long time, and might decrease the lifetime of the animals. By this way, the owner of the dog with atopia, must know about the complications of the disease, and occasional return of the clinical signs during the period of treatment. Therefore, this article has an objective of a review about Canine Atopic Dermatitis that is an increasing problem in the small animal practice.
\end{abstract}

Key words: Atopia, pruritus, dogs, atopic dermatitis

1 Graduanda em Medicina Veterinária da UEL

2 Docente do Depto de Clínica Veterinária da UEL. Rodovia Celso Garcia Cid, Pr 445, Km 380. E-mail: ??? Campus Universitário, Cx. Postal 6001. CEP 86051-990 Londrina - PR Fone/fax: (43) 3371-4485

3 Residente da área de Clínica Médica da Escola de Veterinária da UFMG

4 Médica Veterinária Autônoma

5 Docente do Departamento de Clínicas Veterinárias da UFMG

* Autor para correspondência 


\section{Introdução}

A Dermatite Alérgica Canina (DAC) é uma doença de pele de caráter genético e inflamatório (DEBOER, 2004; SOUSA; MARSELLA, 2001), na qual o paciente torna-se sensibilizado a antígenos ambientais mediante a formação de anticorpos $\operatorname{IgE}$ (SCOTT; MILLER; GRIFFIN, 1996; GORMAN, 1997; WHITE, 1998; OLIVRY et al., 2001), que causa afecção alérgica pruriginosa (OLIVRY et al., 2001).

A atopia canina é o segundo distúrbio cutâneo alérgico mais comum, sendo menos freqüente apenas que a dermatite alérgica à picada de pulgas (WHITE, 1998; HILLIER; GRIFFIN, 2001; SOUSA; HALLIWELL, 2001; SCOTT; MILLER; GRIFFIN, 2001). Algumas raças são mais predispostas a desenvolverem a dermatite atópica (SOUSA; MARSELLA, 2001) como Shar Pei, West Highland White Terrier, Scoth Terrier, Lhasa Apso, Shih Tzu, Fox Terrier de Pêlo Duro, Dálmata, Pug, Setter Irlandês, Boston Terrier, Golden Retriever, Boxer, Setter Inglês, Labrador, Schnauzer Miniatura, Pastor Belga (SCOTT; MILLER; GRIFFIN, 1996) e Buldog Inglês (WHITE, 1998; GRIFFIN; DEBOER, 2001). Outras raças são citadas com menor freqüência: Pastor Alemão, Cocker Spaniel, Dachshund, Doberman e Poodle Gigante (GRIFFIN; DEBOER, 2001). A DAC também pode acometer cães mestiços (WHITE, 1998).

Em relação ao sexo, há divergência em relação aos autores. Alguns relatam incidência maior em fêmeas ao passo que outros descrevem maior manifestação da DAC em machos (SCOTT; MILLER; GRIFFIN, 1996; THOMPSON, 1997; WHITE, 1998; GRIFFIN; DEBOER, 2001).

A idade em que os sinais clínicos se iniciam varia de seis meses a sete anos, sendo que, cerca de $70 \%$ dos cães desenvolvem o problema entre 1 e 3 anos de idade (SCOTT; MILLER; GRIFFIN, 1996; WHITE, 1998; GRIFFIN; DEBOER, 2001). Entretanto, Shar Peis, Akitas e Golden Retrievers podem ocasionalmente apresentar atopia antes dos 6 meses de idade.

\section{Etiologia}

Os antígenos responsáveis por desencadear a resposta imune observada na DAC recebem o nome de alérgenos e estão no ambiente, promovendo uma hipersensibilidade do tipo I (OLIVRY et al., 2001; ALVES; AMANO; MARINO, 2002). Estes alérgenos são bolores, polens, debris da epiderme humana, sementes de gramíneas, penas, paina e a poeira doméstica, a qual é constituída da mistura de resíduos de pele humana, pêlos de animais, ácaros, bolores, produtos de decomposição, partículas alimentares e substâncias inorgânicas (SCOTT; MILLER; GRIFFIN, 1996; THOMPSON, 1997; WHITE, 1998; HILL; DEBOER, 2001; ALVES; AMANO; MARINO, 2002; HILLIER, 2002). Entre os ácaros de poeira doméstica, destaca-se o Dermatophagoides farinae (SCOTT; MILLER; GRIFFIN, 1996).

As diferenças regionais dos alérgenos em decorrência dos tipos de fauna e flora (THOMPSON, 1997), e o estilo de vida de cada região (HILL; DEBOER, 2001) é algo importante a ser considerado. Além disso, os sinais clínicos iniciais podem manifestar-se em determinada época do ano, dividindo a DAC em sazonal e não sazonal. Nos Estados Unidos, cerca de $80 \%$ doas cães com atopia sazonal manifestam sinais clínicos iniciais no período da primavera ao outono e $20 \%$ apresentam sintomatologia no inverno (SCOTT; MILLER; GRIFFIN, 1996; GRIFFIN; DEBOER, 2001). Eventualmente, alguns pacientes desenvolvem a forma de atopia não sazonal, na qual o prurido ocorre durante todo o ano, porém, há agravamento dos sinais nos meses mais quentes (HILLIER, 2002). Nesses pacientes, a doença tende a se tornar mais crônica (HILLIER, 2002).

Acredita-se que os cães geneticamente predispostos absorvem por via percutânea, inalam (SCOTT; MILLER; GRIFFIN, 1996, 2001; THOMPSON, 1997; WHITE, 1998; ALVES; AMANO; MARINO, 2002; DEBOER, 2004) ou ingerem diversos alérgenos (WHITE, 1998). Em 
relação à absorção pela cútis, alguns autores inferem que há um aumento na penetração dos antígenos, devido a uma disfunção da barreira lipídica epiderme (SCOTT; MILLER; GRIFFIN, 1996; DEBOER, 2004). Isso ocorre por combinação deficiente de organelas lipídicas de superfície, existentes entre os espaços intercelulares, como é sugerido na atopia humana (OLIVRY; HILL, 2001a). Dessa forma, há mudança na composição química da barreira lipídica epidérmica e um aumento na perda de água via transepidermica. Em um estudo, verificou-se que os valores de perda e absorção de água não foram diferentes entre cães atópicos e normais.

Marsella (2006) relata que a deposição da lamina lipídica do estrato córneo na pele de cães atópicos mostrou-se marcadamente heterogênea comparada com a pele de cães normais. Olivry et al. (2001) realizaram um trabalho por meio do qual compararam a pele de cães atópicos com a de cães normais, utilizando microscopia eletrônica, e demonstraram as diferenças estruturais dos lipídeos presentes no estrato córneo nestes dois grupos.

\section{Fisiopatologia}

Hipersensibilidade é caracterizada por reações provenientes de resposta imune protetora, porém exagerada e deletéria, contra determinado antígeno (GORMAN, 1997; OLIVRY et al., 2001). Segundo Scott, Miller e Griffin (1996) e Gorman (1997), os distúrbios da hipersensibilidade clínica são divididos em quatro tipos (I, II, III e IV), de acordo com a base imunológica.

As reações do tipo I são aquelas que envolvem predisposição genética, produção de anticorpos reagentes, além da degranulação de mastócito. São reações que geralmente se iniciam após o segundo contato com o antígeno, sendo também chamadas de reaçõesimediatas(GORMAN, 1997).ADACenvolve este tipo de reação, que é mediada principalmente pela IgE (SCOTT; MILLER; GRIFFIN, 1996; THOMPSON, 1997; GORMAN, 1997; WHITE, 1998). Uma vez feito o contato com o alérgeno, as células de Langerhans entram em contato com este e os linfócitos T auxiliares são requisitados para fazerem a apresentação do atígeno aos linfócitos B (WHITE, 1998). Estes produzem anticorpos IgE alérgenoespecíficos e células de memória. Os anticorpos $\operatorname{IgE}$ se ligam aos mastócitos e basófilos teciduais, o que resulta em degranulação dos mastócitos e liberação de mediadores inflamatórios pré-formados, além da estimulação da cascata do ácido aracdônico (WHITE, 1998). Esses mediadores pré-formados são: histamina, heparina, serotonina, cininogenase, proteases neutras, fator quimiotático eosinofílico da anafilaxia, fator quimiotático do neutrófilo, fator ativador das plaquetas (GORMAN, 1997; DEBOER, 2004) e todos os derivados do ácido aracdônico. Este último é ativado por uma entre duas vias, a lipoxigenase, que leva à formação de leucotrienos, ou a cicloxigenase, que leva à formação de prostaglandinas (GORMAN, 1997). Os leucotrienos e a histamina aumentam a permeabilidade vascular e induz a contração da musculatura lisa (o primeiro relacionado particularmente à árvore brônquica e a segunda relacionada à secreção exócrina). Assim, ocorre resposta bifásica iniciada tanto por mediadores solúveis quanto por células inflamatórias. A combinação dos mediadores inflamatórios préformados e derivados do ácido aracdônico resulta no desenvolvimento dos sinais de inflamação, como eritema, edema e prurido (WHITE, 1998). Contudo, clinicamente não está bem estabelecido qual é o mediador mais relevante em relação à manifestação dos sinais da DAC em cães (MARSELLA; OLIVRY, 2001a).

Marsella 2006 apud Egli 2002relata que foram feitas tentativas de se estabelecer um modelo clínico para atopia canina, mediante o uso de altas doses de IgE, porém, verificou-se sucesso limitado neste experimento. (EGLI 2002 apud MARSELLA, 2006). Achados desta natureza, talvez expliquem as especulações de que diferentes formas de $\operatorname{IgE}$, possuam diferentes potenciais patogênicos e que há mecanismos adicionais podendo exercer papéis decisivos na patogenia da dermatite atópica. 
Segundo Marsella (2006), quando se compara cães atópicos a cães normais, verifica-se que há uma "superexpressão" da interleucina (IL) - 4 nos primeiros (MARSELLA, 2006).

Algumas áreas da pele apresentam maior predileção para manifestação dos sinais de atopia, são elas: pavilhões auriculares e membros. Nelas, a concentração de mastócitos é maior (AUXILIA; HILL, 2000).

Recentemente identificou-se um subtipo de atopia, chamada atopia "intrínseca" ou "não-alérgica", na qual respostas a IgE não foram detectadas, entretanto, os indivíduos apresentam os sinais clínicos típicos de DAC (MARSELLA, 2006).

\section{Sinais clínicos}

O sinal clínico inicial da DAC é prurido em áreas sem lesão visível ou com máculas eritematosas (SCOTT; MILLER; GRIFFIN, 1996). Pode ser localizado ou generalizado. O primeiro ocorre principalmente na face, pavilhão auricular, extremidades distais dos membros (SCOTT; MILLER; GRIFFIN, 1996; KWOCHKA, 1998; GRIFFIN; DEBOER, 2001), axilas e região inguinal (KWOCHKA, 1998; OLIVRY; HILL, 2001b). O segundo é relatado em cerca de 40\% dos cães atópicos (SCOTT; MILLER; GRIFFIN, 1996; GRIFFIN; DEBOER, 2001). Em virtude do prurido, pode-se observar também lambedura dos membros, atrito da face contra o chão, lesões axilares, entre outros (THOMPSON, 1997). Estas manifestações contribuem para o desenvolvimento de infecções e podem originar lesões secundárias como alopecia focal ou difusa, pústulas, máculas, edema, liquenificação, hiperpigmentação e em animais de pelame claro pode ocorrer discromia ferruginosa devido à lambedura excessiva (WHITE, 1998; GRIFFIN; DEBOER, 2001; SCOTT; MILLER; GRIFFIN, 2001). As lesões crônicas são observadas principalmente nos locais onde há prurido intenso e repetido.
Diferente dos outros cães, o Buldog Inglês atópico quase sempre apresenta eritema, edema e lesões cutâneas secundárias, mas pouco ou nenhum prurido (SCOTT; MILLER; GRIFFIN, 1996; GRIFFIN; DEBOER, 2001).

A otite externa e o prurido do pavilhão auricular ocorrem em aproximadamente $86 \%$ dos pacientes (GRIFFIN; DEBOER, 2001). Conjuntivite, epífora e blefaroespasmo podem estar presentes em 50\% dos casos (SCOTT; MILLER; GRIFFIN, 1996; GRIFFIN; DEBOER, 2001; OLIVRY; HILL, 2001b).

Seborréia acentuada é observada em 12 a 23\% dos cães atópicos (GRIFFIN; DEBOER, 2001).

A piodermite estafilocócica acomete em torno de $68 \%$ dos cães atópicos. Geralmente é superficial, mas pode ser profundo em alguns casos (HILLIER, 2002).

Alguns cães atópicos desenvolvem sinais não cutâneos, como rinite, catarata, asma (SCOTT; MILLER; GRIFFIN, 1996; OLIVRY; HILL, 2001b), ceratoconjuntivite seca, distúrbios urinários, gastrointestinais e hipersensibilidade hormonal. Cadelas podem apresentar ciclos estrais irregulares, taxa de concepção diminuída e incidência elevada de pseudociese (SCOTT; MILLER; GRIFFIN, 1996; DEBOER, 2004).

\section{Diagnóstico}

O plano diagnóstico inicia-se com o intuito de promover o controle em relação aos fatores perpetuantes. Assim sendo, é necessário se estabelecer os possíveis diagnósticos diferenciais, baseados na resenha, histórico e sinais clínicos.

O diagnóstico definitivo da dermatite atópica geralmente não é dado na primeira consulta. Realizar raspado cutâneo (deve ser feito de vários lugares para as espécies tipos de Demodex) e exame micológico (direto e cultura) são imperativos para qualquer paciente portador de dermatopatia, salvo exceções, 
como nos casos de neoplasia cutânea. Numa segunda etapa, realizar uma triagem terapêutica com uso, por exemplo, de Anti-histamínicos ou corticóides, torna-se um dos pontos principais para se confirmar ou excluir alguns dos diagnósticos diferenciais (HILLIER, 2002).

Devem-se obter amostras da superfície da pele em mais de um local acometido, por meio de "imprint", para realização de exame citológico (HILLIER,
2002). Fazer swab de pústulas para a cultura bacteriana se houver uma resposta inapropriada a antibioticoterapia. O exame citológico, bem como a cultura bacteriana das orelhas acometidas também é indicado (HILLIER, 2002). Este mesmo autor sugere um algoritmo para facilitar o diagnóstico da atopia em cães.

Algoritmo para diagnóstico da DAC, segundo Hillier, 2002:

História e sinais clínicos sugestivos de dermatite atópica, identificar e controlar fatores perpetuantes, incluindo piodermite, malasseziose, otite externa, demodiciose e doenças crônicas da pele. Identificar e tratar o cão para dermatite alérgica a pulgas e escabiose se indicado.

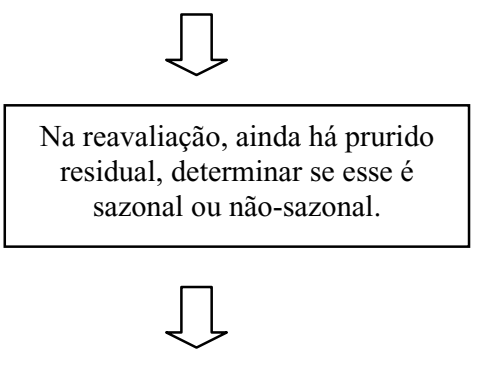

Se o prurido é não sazonal, o cão tem uma hipersensibilidade alimentar, DAC ou dermatite por contato (rara). Para distinguir entre elas, estabelecer a dieta hipoalergênica por quatro a doze semanas

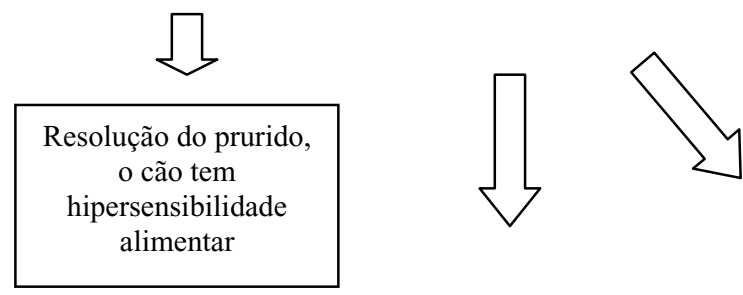

Não houve melhora, o cão tem DAC
Se na reavaliação não há prurido residual, o cão tinha dermatite alérgica à pulgas, escabiose, DAC sazonal,. Manter o controle de pulgas e monitorar a recorrência de prurido.
Se o prurido é sazonal, o cão tem ou uma DAC sazonal ou uma hipersensibilidade à picada de insetos.(incomum)
Melhora parcial do prurido, hipersensibilidade alimentar com DAC
Após a confirmação da DAC, a detecção dos alérgenos envolvidos no quadro pode ser feita com o teste intradérmico e testes alérgicos in vitro ou sorológicos (SCOTT; MILLER; GRIFFIN, 1996).

O teste intradérmico é considerado o único método in vivo aceito para investigações a respeito de drogas antialérgicas (THOMPSON, 1997; HILLIER; DEBOER, 2001), sendo o preferido na detecção dos alérgenos causadores de sinais nos cães (SCOTT; MILLER; GRIFFIN, 1996). Ele consiste na injeção intradérmica dos alérgenos suspeitos e na observação da hipersensibilidade do tipo imediata, ou seja, a presença de rubor e pápula no local, que 
podem ser graduados subjetivamente por meio de inspeção visual e palpação (THOMPSON, 1997). Porém, um resultado positivo não é um pré-requisito para o diagnóstico de DAC, sendo mais útil para selecionar alérgenos (HILLIER, 2002)

Não há padronização dos extratos alérgenos para o teste disponível em medicina veterinária, tornando difícil sua seleção e diluição (SCOTT; MILLER; GRIFFIN, 1996; HILLIER; DEBOER, 2001). Alérgenos aquosos são mais utilizados, pois aqueles com glicerina são considerados irritantes. O uso de alérgenos mistos não é recomendado, pois freqüentemente resultam em reações falsonegativas, já que alérgenos individuais podem estar em concentração muito diluída para a detecção (SCOTT; MILLER; GRIFFIN, 1996; HILLIER; DEBOER, 2001).

Ressalta-se que a reação positiva ao teste, significa que o paciente possui anticorpos sensibilizantes na pele, e não necessariamente que ele possua alergia clínica. Assim, é necessário que as respostas positivas sejam interpretadas correlacionandoas com o histórico do animal (SCOTT; MILLER; GRIFFIN, 1996; HILLIER; DEBOER, 2001).

O uso de Anti-histamínicos deve ser interrompido por aproximadamente 10 (SCOTT; MILLER; GRIFFIN, 1996; HILLIER; DEBOER, 2001) a 14 dias (WHITE, 1998) antes do teste. Quanto aos glicocorticóides, os de uso tópico e os de curta duração, devem ser interrompidos por no mínimo 3 semanas (SCOTT; MILLER; GRIFFIN, 1996; WHITE, 1998; HILLIER; DEBOER, 2001). Os de longa duração devem ser suspensos por 6 a 12 semanas (WHITE, 1998), com média de 8 semanas (SCOTT; MILLER; GRIFFIN, 1996; HILLIER; DEBOER, 2001). Embora, ainda não se tenha avaliado criticamente drogas antiinflamatórias não esteroidais e a suplementação com ácidos graxos essenciais, essas substâncias podem deprimir a resposta a alérgenos intradérmicos, por alterar a produção de mediadores inflamatórios. Portanto, deve-se interromper seu uso por 2 semanas antes do teste (WHITE, 1998).
Em relação aos testes alérgicos in vitro (testes sorológicos), eles podem ser úteis nas seguintes situações: quando o intradérmico não for uma opção, devido à indisponibilidade, interferência de drogas, comprometimento grave da pele (WHITE, 1998); quando os resultados forem negativos em um cão com grande evidência de DAC ou quando a dessensibilização com base no teste intradérmico for mal sucedida (SCOTT; MILLER; GRIFFIN, 1996, 2001). Estes testes identificam os anticorpos IgE específicos circulantes no soro dos pacientes atópicos (WHITE, 1998). Dentre eles estão: o teste radioalergoabsorvente (RAST), o ensaio imunoabsorvente ligado a enzimas (ELISA) e o ensaio imunoenzimático de fase líquida, que detectam níveis relativos de $\mathrm{IgE}$ alérgeno específicos no soro (SCOTT; MILLER; GRIFFIN, 1996, 2001).

Demonstrou-se que fatores como ecto e endoparasitoses, produzem níveis elevados de $\operatorname{IgE}$ sérica e podem provocar reações falso-positivas no teste alérgico sorológico. Assim sendo, a ocorrência de falsos-positivos nos testes sorológicos é comum, o que caracteriza uma de suas principais desvantagens (SCOTT; MILLER; GRIFFIN, 1996, 2001; WHITE, 1998).

Quando se compara os testes sorológicos com os intradérmicos, verifica-se que eles são mais vantajosos, devido a fatores como não haver necessidade de tricotomia nem de contenção química, nos casos de tratamentos anteriores ou atuais há menor interferência destes nos resultados do teste, pode ser usado em pacientes com dermatite difusa (SCOTT; MILLER; GRIFFIN, 1996, 2001) e também torna-se menos invasivo, pois se necessita apenas de 3 a $5 \mathrm{ml}$ de soro do paciente (WHITE, 1998).

Não há boa correlação entre os resultados dos testes sorológicos com aqueles do teste alérgico intradérmico. Quando a dessensibilização é feita por meio de testes alérgicos sorológicos cuidadosamente interpretados, realizados em pacientes meticulosamente selecionados, cerca 
de $60 \%$ dos cães apresentam respostas boas a excelentes. Esta taxa total de resposta é semelhante àquela relatada para a dessensibilização com base nos resultados para o teste intradérmico. Todavia, a porcentagem de cães com respostas excelentes parece ser mais elevada quando a dessensibilização baseia-se no teste intradérmico. Ocasionalmente cães que possuem testes intradérmicos negativos ou deixaram de responder a dessensibilização por este mesmo meio, responderam bem a dessensibilização com base no teste alérgico sorológico. A discrepância entre o teste sorológico e o teste intradérmico pode ser explicada por inúmeras dificuldades na técnica e sensibilidade. Entretanto, é importante salientar que eles avaliam parâmetros diferentes, de forma que não são esperadas correlações (SCOTT; MILLER; GRIFFIN, 1996, 2001).

Quanto ao exame histopatológico da pele, este foi considerado não específico para diagnóstico de atopia nos cães. Entretanto, se estabeleceu recentemente que essas lesões exibem características inflamatórias com padrão de cronicidade e dermatite perivascular hiperplástica, puras ou espongióticas. São encontradas células epiteliotrópicas como células de Langerhans, linfócitos e raros eosinófilos. $\mathrm{Na}$ derme encontram-se mastócitos, linfócitos e ocasionalmente eosinófilos intactos ou degranulados (OLIVRY; HILL, 2001c).

\section{Tratamento}

O tratamento da DAC consiste na combinação de vários fatores e a consideração de apenas um deles pode levar ao insucesso (OLIVRY; SOUZA, 2001a; DEBOER, 2004). No início deve-se considerar a presença de anormalidades dermatológicas intercorrentes, duração da estação alérgica, gravidade dos sinais clínicos, resposta à terapia médica (WHITE, 1998), distribuição e extensão da pele acometida, desejo do cliente administrar os medicamentos, aceitação pelo paciente e o risco terapêutico. O proprietário deve estar consciente de que o tratamento é vitalício e que as modificações terapêuticas são esperadas ao longo da vida do animal (SCOTT; MILLER; GRIFFIN, 2001).

A opção em relação à terapia irá variar de acordo com o resultado e tipo de testes realizados. Quando há sinais de puliciose, trata-se contra pulgas adultas e em estágios imaturos, presentes no meio ambiente. Todos os animais da casa devem ser tratados. Na presença de piodermite, administrar antibióticos via oral e tópicos (se necessários), xampus antibacterianos ou sprays. Na presença de fungos, a exemplo da malassezíase, a terapia é constituída por antimicótico tópicos e/ou via oral. A tentativa de se eliminar o prurido na fase inicial de tratamento mediante o uso de antiinflamatórios, não é recomendada nas situações em que o (s) fator (res) perpetuante (s) não tenha (m) sido identificado (s) e eliminado (s) (HILLIER, 2002).

A eliminação dos efeitos somatórios e a diminuição do limiar pruriginoso são pontos importantes a serem considerados no início do tratamento. Terapias tópicas, dessensibilização, drogas antipruriginosas sistêmicas, ácidos graxos, Anti-histamínicos e ocasionalmente drogas imunossupressoras constituem o arsenal terapêutico para o tratamento da DAC (SCOTT; MILLER; GRIFFIN, 2001). Adiante, os tipos de terapia serão explicados detalhadamente.

\section{Controle do limiar pruriginoso}

Um dos primeiros passos no tratamento da DAC é o controle do limiar pruriginoso e a eliminação dos efeitos somatórios (OLIVRY; SOUSA, 2001a). Em alguns indivíduos, há o chamado efeito somatório, que ocorre quando mais de um agente que estimula o prurido é necessário para desencadear os sinais clínicos (WHITE, 1998; MARSELLA; SOUSA, 2001). Dessa forma, torna-se imperativo quando for o caso, o controle das outras hipersensibilidades, a exemplo da dermatite alérgica à picada de pulgas, de infecções secundárias e outros fatores estimulantes do limiar pruriginoso (MARSELLA; SOUSA, 2001). 
O uso de antibióticos na maioria das vezes constitui a primeira medida no tratamento da DAC (OLIVRY; SOUSA, 2001a). A droga de escolha é a cefalexina, administrada por via oral na dosagem de $22 \mathrm{mg} / \mathrm{kg}$ a cada oito horas ou $33 \mathrm{mg} / \mathrm{kg}$ a cada 12 horas (WHITE, 1998).

Quando se confirma à presença de malassezíase, antifúngicos (como o cetoconazol, na dosagem de 10 $\mathrm{mg} / \mathrm{kg}$, via oral, a cada oito horas) são necessários como parte coadjuvante do tratamento (OLIVRY; SOUSA, 2001a).

\section{Retirada do alérgeno}

Evitar o contato do paciente com os alérgenos é o ponto chave do tratamento (MARSELLA; SOUSA, 2001). Esta etapa do tratamento depende da cooperação e compreensão dos proprietários, pois leva tempo e é trabalhosa. As medidas a serem adotadas são: cobrir colchões, travesseiros, cama dos cães, cadeiras e sofás com tecidos impermeáveis (como o vinil); manter o canil seco e limpo; assim como a cama do animal; manter o estoque de comida do animal em ambiente seco; manter o animal longe de grama recém cortada, folhas caídas, feno e celeiros; remover colchões das áreas em que o cão dorme para prevenir o acúmulo de poeira e facilitar a limpeza; não permitir ao cão que entre em áreas que tipicamente acumulam poeira, como armários, lavanderia e embaixo das camas e lavar roupa de cama e cobertores toda semana com água quente. Essas recomendações são as mesmas para as pessoas com alergia (HILLIER, 2002).

\section{Imunoterapia}

A imunoterapia alérgeno-específica é um tratamento biológico tipicamente usado para pacientes atópicos, com a finalidade de amenizar os sintomas da doença quando há exposição ao alérgeno. Consiste em administrações subcutâneas de crescentes doses de alérgenos aos quais o animal é sensível (GRIFFIN; HILLIER, 2001; SCOTT;
MILLER; GRIFFIN, 2001). A taxa de sucesso da imunoterapia convencional é de $50 \%$ a $70 \%$ (MARSELLA, 2006).

A vantagem da imunoterapia em relação ao tratamento sintomático convencional inclui a baixa freqüência de administração, o baixo risco de efeitos colaterais devidos à administração prolongada e o potencial de alterar permanentemente o curso da doença (HILLIER, 2002).

O objetivo da terapia consiste em aumentar a capacidade do paciente em tolerar os alérgenos ambientais sem sinais clínicos. A imunoterapia permite a redução significativa na terapia farmacológica sintomática e ocasionalmente sua eliminação (WHITE, 1998).

Acredita-se que os efeitos benéficos da imunoterapia têm relação com a teoria do anticorpo de bloqueio, que propõe que o paciente responda formando anticorpos específicos. Esses anticorpos circulantes são protetores, por se ligarem ao alérgenos invasores antes que esses atinjam a $\operatorname{IgE}$ ou IgGd específicas. Outros mecanismos são propostos como a redução ou diminuição em longo prazo da sensibilidade celular do anticorpo disponível para sensibilizar células liberadoras de mediadores da inflamação (SCOTT; MILLER; GRIFFIN, 2001), dessensibilização humoral levando a redução dos níveis de IgE e dessensibilizaçao celular com reatividade reduzida dos mastócitos e basófilos. (SCOTT; MILLER; GRIFFIN, 2001).

A vacina é feita para cada paciente com base nos resultados dos testes intradérmicos e sorológicos. Para a confecção dessa vacina podem ser usados três tipos de alérgenos: em emulsão, precipitados em alúmen e aquosos. Os alérgenos aquosos são mais vantajosos, pois são mais rapidamente absorvidos, necessitam de doses menores e requerem injeções múltiplas e freqüentes, sendo os mais utilizados nesse procedimento (SCOTT; MILLER; GRIFFIN, 2001).

A imunoterapia para cães não é padronizada, havendo variações no tipo do alérgeno, número e 
freqüência de administração na fase de indução, dose, potencia do extrato e via de administração (GRIFFIN; HILLIER, 2001; SCOTT; MILLER; GRIFFIN, 2001). Todos os protocolos da imunoterapia exigem período de indução seguido por dosagem de manutenção. Uma vez alcançada a dose de manutenção, repete-se a aplicação a cada três semanas durante todo o ano (WHITE, 1998).

Para diminuir o período de indução, protocolos de uma imunoterapia mais rápida têm sido explorados na medicina veterinária. Em um estudo, extratos de alérgenos foram administrados em concentrações aumentadas a cada 30 minutos durante 6 horas até a concentração de manutenção de 20.000 PNU/ml. Os autores desse estudo concluíram que a imunoterapia rápida é um método seguro para tratamento de cães com dermatite atópica (MARSELLA, 2006), sendo utilizada para substituir o período de indução prolongada (de 15 semanas para até 4 semanas). Os riscos do uso de imunoterapia de forma mais rápida incluem aumento no prurido e necessidade de suspender o tratamento (MARSELLA, 2006).

As reações adversas da imunização são raras, mas podem ocorrer em até $5 \%$ dos pacientes e são tratadas de acordo com os sinais (WHITE, 1998). Edema localizado, eritema, dor e prurido podem ser observados no local da injeção. O tratamento prévio com Anti-histamínicos pode controlar esse tipo de reação (GRIFFIN; HILLIER, 2001).

Os benefícios da imunoterapia são comprovados e cerca de 50 a $80 \%$ das respostas são consideradas boas a excelentes demonstrando melhora clínica dos pacientes (SCOTT; MILLER; GRIFFIN, 1996; WHITE, 1998). É bem aceito que esse tratamento é eficiente, valioso e relativamente seguro para cães atópicos (SCOTT; MILLER; GRIFFIN, 2001).

\section{Terapia tópica}

$\mathrm{O}$ tratamento tópico tem como objetivo à remoção dos alérgenos da pele. O uso de agentes tópicos antipruriginosos é geralmente mais eficiente no tratamento de áreas localizadas de prurido. Em geral, a maioria dos cães atópicos deve ser banhada a cada uma ou duas semanas com xampus hipoalergênicos e coloidais contendo aveia (SCOTT; MILLER; GRIFFIN, 2001). Xampus antibacterianos e antiseborréicos também auxiliam no tratamento de infecções e dermatite seborréica secundárias, respectivamente (WHITE, 1998).

\section{Anti-histamínicos}

Os Anti-histamínicos são freqüentemente recomendados para o tratamento sintomático do prurido na dermatite atópica canina. Sua ação é a de inibiros efeitos fisiológicos dahistamina, bloqueando seus receptores. Desta forma, interferem na liberação de mediadores inflamatórios, recrutamento de células inflamatórias, permeabilidade vascular e conseqüentemente no prurido (DEBOER; GRIFFIN, 2001). O efeito adverso mais comum está relacionado ao SNC, como letargia, depressão, sedação e sonolência. Efeitos gastrointestinais também podem ocorrer como vômito, diarréia, anorexia e constipação. Entretanto, são incomuns e podem estar sem amenizados com a administração do medicamento junto com a comida (SCOTT; MILLER, 1999).

Os Anti-histamínicos mais utilizados na DAC são o maleato de clorfeniramina $(0,2-0,5 \mathrm{mg} / \mathrm{kg})$, difenidramina $(2,2 \mathrm{mg} / \mathrm{kg})$, hidroxizine $(2,2 \mathrm{mg} /$ $\mathrm{kg})$ e fumarato de clemastina $(0,05-0,1 \mathrm{mg} / \mathrm{kg})$ (WHITE, 1998; SCOTT; MILLER; GRIFFIN, 2001; HILLIER, 2002). O efeito benéfico dessas drogas, quando usadas isoladamente, ocorre entre 7 a 14 dias (DEBOER; GRIFFIN, 2001). Além disso, a resposta aos Anti-histamínicos é muito individualizada e são ineficientes em pacientes com prurido intenso (SCOTT; MILLER; GRIFFIN, 1996).

\section{Ácidos graxos}

O uso de ácidos graxos essenciais no tratamento do prurido crônico foi amplamente estudado e seu 
efeito benéfico foi comprovado por vários autores. Segundo Scott, Miller e Griffin (1996), eles são eficazes em cerca de $15 \%$ dos cães atópicos. Os ácidos graxos essenciais linolênico, alfa-linolênico, araquidônico e poliinsaturados ômega 3 e ômega 6 são incorporados no interior de todas as membranas celulares. Eles são exigidos para todas as estruturas e funções da membrana celular, não são sintetizados e, portanto devem ser fornecidos na dieta (WHITE, 1998).

Teoricamente, cães com dermatite atópica canina são mais responsivos a suplementos com ácidos graxos que contêm baixas doses de ácido linoléico (LA) e altas doses de ácido $\gamma$-linolênico (GLA) e/ou ácido eicosapentaenóico(EPA). Estes, incorporados à membrana celular competem com o ácido aracdônico (AA) pelas enzimas cicloxigenase e lipoxigenase (WHITE, 1995) diminuindo, portanto, a produção de leucotrienos e prostaglandinas, apresentando, portanto, ação antiinflamatória (SCOTT; MILLER; GRIFFIN, 1996; DEBOER, 2004).

Sugere-se que cães com atopia exibem anormalidades nos lipídios que formam a proteção da epiderme, levando à perda de água e hiperidrose (OLIVRY; HILL, 2001b; OLIVRY; MARSELLA; HILLIER, 2001). Desta forma, há evidências de que a administração oral de altas doses de ômega 6 poderia melhorar os sinais clínicos provocados por tal alteração. A suplementação de ácidos graxos na dieta poderia, portanto, diminuir a perda de água pela pele. O mecanismo sugerido é que essas substâncias se incorporam aos lipídeos intracelulares da epiderme(OLIVRY; MARSELLA; HILLIER, 2001; DEBOER, 2004). Assim, como a perda de água está aumentada em cães atópicos, a suplementação oral com ácidos graxos essenciais e a aplicação tópica de óleos poderiam levar à normalização da barreira epidérmica (MARSELLA, 2006).

As dosagens indicadas são $40 \mathrm{mg} / \mathrm{kg}$ de ácido graxo ômega 3 e 60 a $138 \mathrm{mg} / \mathrm{kg}$ de ácido graxo ômega 6 , administrados por via oral uma vez ao dia (HILLIER, 2002).
Obtêm-se efeitos sinérgicos quando se utiliza ácidos graxos associados à Anti-histamínicos ou a glicocorticóides (WHITE, 1998). O uso adequado dos agentes não esteróides pode permitir que até $60 \%$ dos casos de DAC sejam satisfatoriamente tratados sem glicocorticóides. Além disso, a associação de ácidos graxos permite freqüentemente redução nas doses de requeridas de glicocorticóides (SCOTT; MILLER; GRIFFIN, 2001). Alguns efeitos adversos após o uso prolongado de ácidos graxos ômega 3 podem ocorrer, como um aumento no risco de sangramentos associado à disfunção plaquetária e fibrinólise. A função plaquetária pode ser alterada pelos ácidos graxos ômega 3, pois esses são incorporados à membrana das plaquetas (HALL, 1996).

Além disso, o uso prolongado de ômega 3 tem o potencial de induzir à peroxidação e à formação de lipofuscina no tecido. $O$ acúmulo de lipofuscina pode afetar a viabilidade e a função celular e o acúmulo de ácidos graxos no tecido os deixa mais pré-disposto à peroxidação lipídica (HALL, 1996). A suplementação com ácido graxo ômega $3 \mathrm{em}$ humanos com diabetes do tipo II, provocou um aumento da taxa de glicose sanguínea, sem aumento na taxa de insulina (HALL, 1996).

\section{Glicocorticóides}

Os glicocorticóides sistêmicos são geralmente muito eficazes no tratamento da DAC, entretanto, são consideradas as drogas potencialmente mais danosas dentre as utilizadas, devido aos possíveis efeitos colaterais. Por essa razão, seu uso deve ser limitado aos períodos ativos da doença com duração menor que 4 meses ou naqueles em que os Antihistamínicos e a imunoterapia não foram eficazes (SCOTT; MILLER; GRIFFIN, 1996, 2001).

Os glicocorticóides previnem a ativação de muitas células do sistema imune, como linfócitos $\mathrm{T}$, eosinófilos, células dendríticas e macrófagos, que estão envolvidas na inflamação e na alergia. Também agem suprimindo produção de citocinas, como 
interferon gama e interleucinas (OLIVRY; SOUSA, 2001b). A produção de anticorpos não é suspensa, apenas diminuída. Em níveis farmacológicos, os glicocorticóides bloqueiam a ação da fosfolipase $\mathrm{A}_{2}$ nas membranas celulares, o que resulta na inibição da cascata do ácido araquidônico, produtor de potentes mediadores inflamatórios (OLIVRY; SOUSA, 2001b; SCOTT; MILLER; GRIFFIN, 2001).

A prednisona via oral é o glicocorticóide de escolha para o tratamento de DAC (OLIVRY; SOUSA, 2001 a; OLIVRY; SOUSA, 2001b; SCOTT; MILLER; GRIFFIN, 2001). O esquema terapêutico mais utilizado consiste em indução e manutenção (SCOTT; MILLER; GRIFFIN, 2001). A dosagem de indução comumente usada é de $1,1 \mathrm{mg} / \mathrm{kg}$ a cada 24 horas. Entretanto, nos quadros graves, usa-se a dosagem de 1,75 a 2,0 mg/kg/dia. Geralmente essas dosagens são administradas durante 3 a 10 dias, a cada 24 horas ou divididas a cada 12 horas durante 2 a 4 dias, seguidas da dosagem total a cada 24 horas até o $10^{\circ}$ dia. Mantém-se este esquema até que os sinais da doença estejam controlados. Após, iniciase o protocolo da terapia de manutenção (SCOTT; MILLER; GRIFFIN, 2001), com intuito de se atingir valores entre 0,25 a $0,5 \mathrm{mg} / \mathrm{kg}$ a cada 48 horas. Na terapia de manutenção a dosagem em dias alternados sofre redução pela metade a cada 1 ou 2 semanas. Este esquema não diminui alguns efeitos colaterais, como a hipotrofia adrenal, mas os torna menos grave e de início tardio (SCOTT; MILLER; GRIFFIN, 2001).

Nos cães, os efeitos colaterais associados ao uso crônico de glicocorticóides sistêmicos são muitos. Entre eles está a poliúria, polidipsia, alopecia, polifagia, obesidade, infecções urinárias do trato inferior, (OLIVRY; SOUSA, 2001b; SCOTT; MILLER; GRIFFIN, 2001) até efeitos mais graves como pancreatite, ulceração e perfuração gastrintestinal (OLIVRY; SOUSA, 2001b; SCOTT; MILLER; GRIFFIN, 2001) e miopatias (SCOTT; MILLER; GRIFFIN, 1996, 2001).

\section{Ciclosporina}

A ciclosporina é um metabólito polipeptídico cíclico lipossolúvel derivado do fungo Tolypocladium inflantum gams (SCOTT; MILLER; GRIFFIN, 1996, 2001; MARSELLA; OLIVRY, 2001b). Em dermatologia humana têm se mostrado útil no tratamento da psoríase e dermatite atópica. $\mathrm{Na}$ dermatologia canina, tem sido objeto de crescente interesse para o tratamento da fístula perianal e dermatite atópica. Em cães e em seres humanos, a ciclosporina é metabolizada pelo fígado e intestino, sendo que nos primeiros, ela sofre metabolismo hepático 3 vezes mais ativo que em humanos (GUAGUÈRE; STEFAN; OLIVRY, 2004).

A ciclosporina possui propriedades antiinflamatórias inibindo a ativação de vários tipos celulares envolvidos na inflamação da alergia cutânea (MARSELLA; OLIVRY, 2001b; DEBOER, 2004). Também atua contra a degranulação dos mastócitos, age diretamente na inibição da histamina (SCOTT; MILLER; GRIFFIN, 2001), e bloqueia a proliferação de linfócitos $\mathrm{T}$ ativados pela inibição da inteleucina 2, ativação genética e transcrição do RNA mensageiro. Além disso, ela bloqueia receptores de superfície de células $\mathrm{T}$ (SCOTT; MILLER; GRIFFIN, 2001).

É necessário tratamento por no mínimo 30 dias até se observar resposta clínica (HILLIER, 2002). Um recente estudo foi desenvolvido sobre o uso da ciclosporina no controle e tratamento da dermatite atópica canina, com $71 \%$ a $75 \%$ de taxa de satisfação dos clientes (BRUNER, 2006).

A administração oral de ciclosporina na dosagem de $5 \mathrm{mg} / \mathrm{kg}$ apresentou eficácia similar à da predinisolona na dosagem de $0,5 \mathrm{mg} / \mathrm{kg}$ em um estudo de 6 semanas (MARSELLA, 2006). Recomenda-se a administração da ciclosporina 2 horas antes ou após a alimentação (BRUNER, 2006). Quando aplicada via percutânea, tem pobre penetração devido à presença de muitos lipídeos solúveis (BRUNER, 2006). 
Guaguère, Stefan e Olivry (2004) relata um trabalho em que o objetivo fora comparar a eficácia da ciclosporina versus o uso de glicocorticóides no tratamento da atopia canina. Ambas as medicações resultaram em uma melhora similar nas lesões da pele e no prurido, entretanto, verificou-se que a incidência de infecções bacterianas na pele, foi menor em cães recebendo ciclosporina do que nos tratados com metilprednisolona. Para tratamentos de longa duração, a ciclosporina torna-se uma alternativa.

Em cães, os efeitos colaterais são incomuns e surgem quando se usa a ciclosporina na dosagem de 5 a $10 \mathrm{mg} / \mathrm{kg}$. Esses efeitos são: nefrotoxicidade, hipertensão, hepatotoxicidade (BRUNER, 2006), hiperplasia gengival, periodontite, papilomatose cutânea, vômito, diarréia, bacteriúria, infecção cutânea bacteriana, anorexia, supressão da medula óssea e dermatose linfoplasmocitóide (MARSELLA; OLIVRY, 2001b; SCOTT; MILLER; GRIFFIN, 2001). Além disso, ela pode predispor ao desenvolvimento do linfoma (MARSELLA, 2006). O tratamento prolongado está associado a lesões irreversíveis do parênquima renal quando se utiliza altas doses (20 $30 \mathrm{mg} / \mathrm{kg}$ ) de ciclosporina. Nesses casos verificou-se redução do fluxo urinário e da excreção de sódio, porém sem alterção do clearance renal. Entretanto, em estudos toxicológicos conduzidos em cães utilizando a ciclosoporina na dosagem de $45 \mathrm{mg} / \mathrm{kg}$ durante 52 semanas, não foram observados sinais de nefrotoxicidade em relação à ao aspecto clínico e histológico. (GUAGUÈRE; STEFAN; OLIVRY, 2004).

\section{Tracolimus}

O tracolimus é uma lactona macrolítica produzida pelo fungo Streptomyces tsukubaensis e, embora seja distinto quimicamente da ciclosporina, seu mecanismo de ação é semelhante, inibindo a resposta dos linfócitos $\mathrm{T}$ aos antígenos e a produção de citocinas responsáveis pela proliferação destes. Estima-se que ele seja de 10 a 100 vezes mais potente que a ciclosporina (BRUNER, 2006). Uma das vantagens dessa droga é que seu uso pode ser tópico, limitando os riscos de efeitos colaterais sistêmicos. Em cães atópicos seu principal efeito é a diminuição do eritema, contudo a diminuição do prurido não é significativa (MARSELLA; OLIVRY, 2001b).

O ungüento de tracolimus tem se demonstrado seguro e eficazpara o tratamento da atopia em crianças e adultos (MARSELLA, 2006). Quando utilizado a $0,1 \%$ durante 4 semanas, reduziu satisfatoriamente os sinais clínicos da atopia. Poucos estudos têm avaliado a eficácia do tracolimus no tratamento da dermatite atópica canina (MARSELLA, 2006).

É uma droga com baixo peso molecular, que penetra prontamente na pele inflamada, mas pobremente na epiderme normal, levando à hipótese de que quanto menor a inflação da cútis, menor será a sua o seu capacidade de penetração. A aplicação tópica é bem tolerada em cães, podendo ocorrer discreta irritação no local (BRUNER, 2006). Toxicidade e efeitos adversos não foram reportados, além de nenhuma mudança na contagem total de células sanguíneas e parâmetros bioquímicos (MARSELLA, 2006).

\section{Pentoxifilina}

Há relatos do uso de inibidores da fosfodiesterases, como a pentoxifilina $10 \mathrm{mg} / \mathrm{kg}$ via oral, duas vezes ao dia (HILLIER, 2002), para o tratamento da DAC. Esta droga possui propriedades imunomoduladoras e em cães é relatada a supressão da produção de interferons (inibe as propriedades pró-inflamatórias das citocinas). O uso desta droga o prurido e o eritema.

A pentoxifilina é bem tolerada e considerada segura para uso em animais (BRUNER, 2006). Efeitos colaterais graves não foram relatados (MARSELLA; OLIVRY, 2001b), sendo que os mais comuns foram vômito e diarréia. Recomenda-se que ela não seja administrada junto com alimentos. 
Foram relatados efeitos colaterais sobre o sistema nervoso central e cardiovascular em humanos. Além disso, verificou-se que esta substância é excretada no leite e sua segurança durante a gravidez não está bem estabelecida. É metabolizada pelas hemácias e fígado e a via de excreção é a urinária. Sua biodisponibilidade depois da administração oral é de $15 \%$ a $32 \%$ (BRUNER, 2006).

A dosagem depende da doença a ser tratada, e varia de 10 a $40 \mathrm{mg} / \mathrm{kg}$ de uma a três vezes ao dia. A resposta à terapia pode demorar de 1 a 3 meses. Várias formulações genéricas são disponíveis, e alguns autores atribuem isso à diminuição da eficácia ou a um aumento dos efeitos colaterais.

\section{Outras drogas}

O misoprostol é uma prostaglandina análoga com potentes efeitos antialérgicos. Essa droga, entre outras ações, inibe a proliferação dos linfócitos, a ativação granulocítica e a síntese de citocinas próinflamatórias que participam do processo das reações alérgicas. Efeitos adversos podem ocorrer em alguns pacientes, como por exemplo, vômito e diarréia. Não se comprovou totalmente a eficácia deste medicamento (MARSELLA; OLIVRY, 2001b).

O zileuton é um inibidor seletivo da via relacionada à lipoxigenase e também possui efeito supressor sobre a produção de linfócito. Ele é usado com sucesso comprovado no tratamento da dermatite atópica humana. Infelizmente o ainda não existe resultados conclusivos quanto à sua eficácia na espécie canina (MARSELLA; OLIVRY, 2001b).

A fluoxetina é um inibidor da captação da serotonina (MARSELLA; OLIVRY, 2001b; SCOTT; MILLER; GRIFFIN, 2001) e é eficiente em cerca de $30 \%$ dos cães com prurido alérgico. As desvantagens são os efeitos adversos como excitação, poliúria, polidipsia e letargia (HILLIER, 2002). Ainda não há evidências conclusivas para o uso dessa droga no tratamento da DAC (MARSELLA; OLIVRY, 2001b).
Alguns estudos têm sido realizados para testar a eficácia da capsaicina na DAC. A capsaicina é um alcalóide derivado das sementes e membranas de uma planta (uma pimenta conhecida como pimenta chili, com nome científico de Capsicum solanaceae). Seu mecanismo de ação ainda não foi elucidado, mas em humanos é usado topicamente na redução do prurido de várias origens. Não há resultados consistentes de pesquisas feitas com cães que encoraje a recomendação dessa substância no tratamento da dermatite atópica (MARSELLA; OLIVRY, 2001b).

Em seres humanos com asma e rinite alérgica, o uso de um tipo de anticorpo monoclonal (IgG1) contra IgE, tem se mostrado efetivo no tratamento. Ele reconhece e mascara o epítopo na região $\mathrm{CH} 3$ do IgE responsável pela alta afinidade pelos mastócitos e basófilos (MARSELLA, 2006). Desse modo, reduz os níveis séricos de $\operatorname{IgE}$ e regula os receptores $\operatorname{IgE}$ das células dendríticas circulantes. A terapia antiIgE está começando a ser pesquisada em cães, e a vacinação com o peptídeo anti-IgE tem demonstrado uma diminuição do IgE total, controlando os sinais clínicos associados à DAC (MARSELLA, 2006).

\section{Conclusão}

Face ao exposto, pode-se considerar a DAC como uma doença de importância crescente na clínica de pequenos animais. Assim sendo, reconhecer o problema e iniciar terapia adequada são os pontoschaves para conseguir controlar a doença, uma vez que não existe cura. Por ser uma dermatopatia caracterizada por prurido intenso, além do cão, ela gera aflição ao proprietário, que deve ser esclarecido a respeito das recidivas do quadro e do quão é gradual a melhora após iniciar o tratamento.

\section{Referências}

ALVES, F. A. R.; AMANO, L. Y.; MARINO, C. T. Alergias: uma visão geral. Nosso Clínico, São Paulo, v. 5, n. 28, p. 14-20, jul./ago. 2002. 
AUXILIA, S. T., HILL, P. B. Mast cell distribuution, epidermal thickness and hair follicle density in normal canine skin: possible explanations for the predilection sites of atopic dermatits? Veterinary Dermatology, Oxford, v. 11, n. 4, p. 247-254, 2000.

BRUNER, S. R. Updates in therapeutics for veterinary dermatology. Veterinary Clinics Small Animal Practice, Philadelphia, v. 36, n. 1, p. 39-58,2006.

DEBOER, D. J. Canine atopic dermatitis: new targets, new therapies. Madison: American Society for Nutritional Sciences, 2004.

DEBOER, D. J.; GRIFFIN, C. E. The ACVD task force on canine atopic dermatitis (XXI): antihistamine pharmacotherapy. Veterinary Immunology and Immunopathology, Amsterdam, v. 81, n. 3-4, p. 323-329, 2001.

EGLI K.S; SCHIESSL, B.; ROOSJE P.J. Evaluation of the usefulness os sensibilization to aeroallergens as a model for canine atopic dermatitis in genetically predisposed Beagles. American Journal Vterinary Research, v. 63, n. 9, 2002.

GORMAN, N. T. Imunologia. In: ETTINGER, S. J.; FELDMAN, E. C. Tratado de medicina interna veterinária. 4.ed. São Paulo: Manole, 1997. v. 2, p. $2735-$ 2765.

GRIFFIN, C. E.; DEBOER, D. J. The ACVD task force on canine atopic dermatitis (XIV): clinical manifestations of canine atopic dermatitis. Veterinary Immunology and Immunopathology, Amsterdam, v. 81, n. 3-4, p. 255-269, 2001.

GRIFFIN, C. E.; HILLIER, A. The ACVD task force on canine atopic dermatitis (XIV): allergenspecific immunotherapy. Veterinary Immunology and Immunopathology, Amsterdam, v. 81, n. 3, p. 363-383, 2001.

GUAGUÈRE, E.; STEFFAN, J.; OLIVRY, T. Cyclosporin A: a new drug in the field of canine dermatology. Veterinary Dermatology, Oxford, v. 15, n. 2, p. 6174,2004 .

HALL, J. A. Potencial adverse effects of long-term consumption of (n-3) fatty acids. The Compendium of Small Animal, Auburn University College of Veterinary Medicine, v. 18, n 8., p. 879-895, 1996.

HARVEY R.G.; WILKINSON, G.I. Color Atlas of Small Animal Dermatology - A Guide to Diagnosis. 2 ed. Wolfe, 1995.
HILL, P. B.; DEBOER, D. J. The ACVD task force on canine atopic dermatitis (IV): environmental allergens. Veterinary Immunology and Immunopathology, Amsterdam, v. 81, n. 3-4, p. 169-186, 2001.

HILLIER, A. Symposium on atopic dermatits. Veterinary Medicine, Lenexa, KS, v. 97, n. 3, p. 196-222, Mar. 2002.

HILLIER, A.; DEBOER, D. J. The ACVD task force on canine atopic dermatitis (XVII): intradermal testing. Veterinary Immunology and Immunopathology, Amsterdam, v. 81, n. 3-4, p. 289-304, 2001.

HILLIER, A.; GRIFFIN, C. E. The ACVD task force on canine atopic dermatitis (I): incidence and prevalence. Veterinary Immunology and Immunopathology, Amsterdam, v. 81, n. 3-4, p. 147-151, 2001.

KWOCHKA, K. Distúrbios cutâneos e audidivos. In: BICHARD, S. J.; SHERDING, R. G. Manual saunders: clínica de pequenos animais. São Paulo: Roca, 1998. Seção 5, cap. 1, p. 309-306.

MARSELLA, R. Atopy: New targets and new terapies. Veterinary Clinics Small Animal Practice, Philadelphia, v. 36, n. 1, p. 161-174, 2006.

MARSELLA, R.; OLIVRY, T. The ACVD task force on canine atopic dermatitis (VII): mediators of cutaneous inflammation. Veterinary Immunology and Immunopathology, Amsterdam, v. 81, n. 3-4, p. 205-213, $2001 \mathrm{a}$.

. The ACVD task force on canine atopic dermatitis (XXII): nonsteroidal anti-inflammatory pharmacotherapy. Veterinary Immunology and Immunopathology, Amsterdam, v. 81, n. 3-4, p. 331-345, 2001 b.

MARSELLA, R.; SOUSA, C. A. The ACVD task force on canine atopic dermatitis (XIII): threshold phenomenon and summation of effects. Veterinary Immunology and Immunopathology, Amsterdam, v. 81, n. 3-4, p. 251-253, 2001.

OLIVRY, T.; DEBOER, D. J.; GRIFFIN, C. E.; HALLIWELLD, R. E. W.; HILLD, P. B.; HILLIERE, A.; MARSELlAF, R.; SOUSAG, C. A. The ACVD task force on canine atopic dermatitis: forewords and lexicon. Veterinary Immunology and Immunopathology, Amsterdam, v. 81, n. 3-4, p. 143-146, 2001.

OLIVRY, T.; HILL, P. B. The ACVD task force on canine atopic dermatitis (VIII): is the epidermal lipid barrier defective?. Veterinary Immunology and Immunopathology, Amsterdam, v. 81, n. 3-4, p. 215-218, 2001a. 
The ACVD task force on canine atopic dermatitis (IX): the controversy surrounding the route of allergen challenge in canine atopic dermatitis. Veterinary Immunology and Immunopathology, Amsterdam, v. 81, n. 3-4, p. 219-225, 2001 b.

. The ACVD task force on canine atopic dermatitis (XVIII): histopathology of skin lesions. Veterinary Immunology and Immunopathology, Amsterdam, v. 81, n. 3-4, p. 305-309, 2001c.

OLIVRY, T.; MARSELLA, R.; HILLIER, A. The ACVD task force on canine atopic dermatitis (XXIII): are essential fatty acids effective?. Veterinary Immunology and Immunopathology, Amsterdam, v. 81, n. 3-4, p. 347362, 2001.

OLIVRY, T.; SOUSA, C. A. The ACVD task force on canine atopic dermatitis (XIX): general principles of therapy. Veterinary Immunology and Immunopathology, Amsterdam, v. 81, n. 3-4, p. 311-316, 2001a.

. The ACVD task force on canine atopic dermatitis (XX): glucocorticoid pharmaco-therapy. Veterinary Immunology and Immunopathology, Amsterdam, v. 81, n. 3-4, p. 317-322, 2001 b.

SCOTT, D. W.; MILLER, W. H. Antihistamines in the management of allergic pruritus in dogs and cats. The Journal of Small Animal Practice, Oxford, v. 40, n. 8, p. 359-364, 1999.
SCOTT, D. W.; MILLER, W. H.; GRIFFIN, C. E. Small animal dermatology. 6.ed. Philadelphia: W. B. Sauders Company, 2001. p. 667-779.

Dermatologia de pequenos animais. 5.ed. Rio de Janeiro: Interlivros, 1996.

SOUSA, C. A.; HALLIWELL, R. E. W. The ACVD task force on canine atopic dermatitis (XI): the relationship between arthropod hypersensitivity and atopic dermatitis in the dog. Veterinary Immunology and Immunopathology, Amsterdam, v. 81, n. 3-4, p. 233-237, 2001.

SOUSA, C. A.; MARSELLA, R. The ACVD task force on canine atopic dermatitis (II): genetic factors. Veterinary Immunology and Immunopathology, Amsterdam, v. 81, n. 3-4, p. 153-157, 2001.

THOMPSON, J. P. Moléstias imunológicas. In: ETTINGER, S. J.; FELDMAN, E. C. Tratado de medicina interna veterinária. 4.ed. São Paulo: Manole, 1997. v. 2, p. 2766-2802.

WHITE, P. D. Atopia. In: BICHARD, S. J.; SHERDING, R. G. Manual saunders: clínica de pequenos animais. São Paulo: Roca, 1998. p. 343-351.

Essential fatty acids in veterinary medicine.

Kansas: Veterinary Learning Systems, 1995. 
